\title{
Comparative Study of Physico-Mechanical Properties Between Okra and E-glass Fiber-Reinforced Polypropylene-based Composites
}

\author{
Kamrun Nahar Keya, Nasrin Afroz Kona, Ruhul Amin Khan* \\ Radiation and Polymer Composite Laboratory, Institute of Radiation and Polymer Technology, Bangladesh Atomic Energy Commission, \\ Dhaka, Bangladesh \\ Email address: \\ keyakamrun879@gmail.com(K. N. Keya),tamannaafrozkona@yahoo.com (N.A. Kona),dr.ruhul_khan@yahoo.com(R. A. Khan) \\ ${ }^{*}$ Corresponding author
}

To cite this article:

Kamrun Nahar Keya, Nasrin Afroz Kona, Ruhul Amin Khan. Comparative Study of Physico-Mechanical Properties Between Okra and Eglass Fiber-Reinforced Polypropylene-based Composites. Journal of Biomaterials. Vol. 3, No. 2, 2019, pp. 42-49.

doi: $10.11648 /$ j.jb.20190302.12

Received: October 8, 2019; Accepted: November 1, 2019; Published: December 18, 2019

\begin{abstract}
Okra fiber (OF) reinforced polypropylene (PP) matrix composites (45 wt\% fiber) were fabricated using a compression molding technique. To fabricate the composite treated Okra fiber were used. Tensile strength (TS), tensile modulus (TM), elongation at break (Eb\%), bending strength (BS), bending modulus (BM), impact strength (IS) and hardness of the composites were found to be $38.5 \mathrm{MPa}, 0.68 \mathrm{GPa}, 8.2 \%, 72.5 \mathrm{MPa}, 5.56 \mathrm{GPa}, 22.87 \mathrm{~kJ} / \mathrm{m}^{2}$, and 97 (Shore-A), respectively. Then E-glass fiber (woven)-reinforced polypropylene-based composites ( $45 \mathrm{wt} \%$ fiber) were fabricated and the mechanical properties (TS, TM, Eb\%, BS, BM, IS, hardness) were found $80 \mathrm{MPa}, 5 \mathrm{GPa}, 11 \%, 81 \mathrm{MPa}, 10 \mathrm{GPa}, 32 \mathrm{~kJ} / \mathrm{m}^{2}$, and 97 (Shore-A), respectively. After that compared E-glass fiber/PP based composites mechanical properties with those of the OF/PP based composites mechanical properties. It was observed that E-glass fiber-based composites showed almost double mechanical properties compared to OF/PP based composite. Water absorption and elongation percentage at break showed different scenario and it was noticed from the experimental study that water absorption and elongation at break (\%) of was higher than E-glass based composites. After the flexural test, fracture surfaces of the E-glass/PP and OF/PP composites were investigated using scanning electron microscope (SEM) and the results revealed that E-glass fiber reinforced based composites matrix adhesion less than the E-glass fiber reinforced based composites.
\end{abstract}

Keywords: Polypropylene (PP), Okra Fiber (OF), E-glass Fiber, Scanning Electron Microscope (SEM), Mechanical Properties, Matrix Adhesion, Composites

\section{Introduction}

In the last century, synthetic fiber-reinforced polymerbased composites gained huge attention. Synthetic fiberbased composite is now used as a replacement of the conventional structural materials such as metals, wood and reinforced concrete [1]. Day by day it has gained more popularity because of its high stiffness, good processability, fairly cheap, good chemical resistance quality, ease of installation, electrically insulating, higher elongation at break (\%) compared to other materials, high-temperature resistance, fatigue, etc. Several synthetic fibers are now widely used to manufacture the composites [2-3]. Synthetic fibers of reinforcing agents such as E-glass, carbon, aramid, nylon as well as natural fibers like jute, hemp, sisal, Okra, pineapple, kenaf, coir, etc. are being used for manufacturing the composites [4-7]. Among all the synthetic fibers, E-glass fibers are now most common and prominent fiber due to their low cost and comparatively better physical and mechanical properties.

Glass fibers are used as a reinforcing agent during the manufacturing of the composites and the most common types of used glass fiber are E-glass fiber $\left(54.3 \mathrm{SiO}_{2}-15.2 \mathrm{Al}_{2} \mathrm{O}_{3}-\right.$ $17.2 \mathrm{CaO}-4.7 \mathrm{MgO}-8.0 \mathrm{BO}-0.6 \mathrm{Na}_{2} \mathrm{O}$ ). From ancient times, glass fiber has been used in several areas and in 1936, the first time commercially glass fiber has been used. The most 
widely E-glass fiber has good insulation properties, highstrength fabrics, higher elongation at break (\%) than carbon fiber, cheap, good fatigue life, and good corrosion resistance in the most common environments. Many researchers explored their work on E-glass fiber reinforced based composites. E-glass fiber reinforced based composite shows better mechanical properties and better adhesion properties between the fibers and polymer matrix $[8,9]$.

Okra is the most common and well-known natural fibers on earth. Okra is a bast fiber which is collected from the stem of the Okra plant. The scientific name of the plant is Abelmoschus esculentus which is under the family of Malvaceae and this plant is available in Bangladesh as well as other tropical countries around the world [11]. In Bangladesh, the Okra plant is considered as an agricultural wastage product which has no economic value after collecting vegetables. But the mucilage of Okra fiber can be useful for the production of decomposable polymer materials with proper grafting process. Okra fiber is composed of $\alpha$ cellulose $(60-70 \%)$, hemicellulose $(15-20 \%)$, lignin $(5-10 \%)$ and pectin $(3-5 \%)$ [12]. Cellulose is a glucan that is a polymer of the glucose which contains a linear chain of 1, 4-bonded anhydroglucose units and it contains alcoholic hydroxyl groups. Okra fiber is hydrophilic in nature, and this is the most important drawback of this fiber. To reduce these problems, various chemical modification such as mercerization, acetylation, and graft copolymerization, change of functionality have been used [13, 14]. Chemical treatments are used to improve the interfacial properties of the Okra fiber based composites. The present study confirmed that Okra fiber can be used as a reinforcing material and it can be used as a potential candidate to manufacture the composite materials $[15,16]$.

Natural fiber has several advantages like biodegradable, cheaper, recyclable and environmental friendly [17-20]. Although natural fibers have lots of advantages, cellulosic fiber always has some drawbacks as well such as nonresistance to high temperature and experience to moisture absorption [21]. The composite was prepared using thermoplastic matrix and hydrophilic natural fiber which showed less mechanical properties due to a poor affinity between the plastic material and fiber [22]. Many researchers and scientists have been published lots of paper on Okra fibers where Okra was used as reinforcing agent and for fabricating the composite polyethylene (PE) and polypropylene (PP) used as a thermoplastics material with natural (Orka) fibers [23-25].

In this study, polypropylene (PP) was used as a matrix material and using this matrix it showed some excellent results for composite fabrication. Polypropylene (PP) is a thermoplastic polymer and it is widely used in several applications area because of its transparency, flame resistance capability, high heat distortion temperature, dimensional stability, and high impact strength. It can be produced chaingrowth polymerization from monomer propylene [26, 27]. PP always showed good mechanical properties, high chemical resistance. After polyethylene, polypropylene is the most widely used polymer. It is often used in labeling and packaging. For its thermoplastic quality, more than 55 million tons of PP is used for many applications all over the world. Several studies have been already done by the researcher, they used PP with natural fiber for creating natural synthetic polymer composites [28]. In the case of polymer-fiber composite, the quality of the interface is very important because it controls the mechanical and interfacial properties of the resulting composites. PP with biodegradable fibers can be a produced a better combination of syntheticnatural polymer composites [29, 30]. The interfacial properties of the composites can be measured using the single-fiber fragmentation test (SFFT). This method has several advantages such as simple specimen handling, monitoring the failure pattern and processes directly, etc. There are several methods were used to determine the interfacial properties of the fiber-reinforced polymer composites among them most reliable methods were used to determine the interfacial properties of the composites [31].

The performance of the natural fiber based polymer composites based on the nature of the fiber, properties of the natural fiber, the effect of fiber content and the nature of the resin and technique which is used to fabricate composites [32]. Ma et. al. [34] studied that the tensile strength of the micro winceyette fiber reinforced corn starch composites increased when fiber content was increased from 0 to $20 \% \mathrm{wt}$ for making composites. Another researcher found that Lee et. al. [35] investigated that tensile strength and young's modulus of the jute and kenaf fiber reinforced polypropylene based composites increased with the increment of the fiber content and showed maximum results. Potluri R. et. al. studied on the Okra and jute fiber epoxy resin based composite and they found that the mechanical properties and impact strength of the Okra fiber based composite's were better than jute fiber composites [33].

The present investigation involves focusing on two different fibers such as Okra fiber and E-glass fiber to study and measure the mechanical properties of the matrix (PP) and the composites (OF/PP and E-glass fibers/PP). The mechanical properties of $\mathrm{OF} / \mathrm{PP}$ composites were compared over the E-glass fiber/PP composites. The ultimate aim of the present research works was to compare the mechanical and interfacial properties between $\mathrm{OF} / \mathrm{PP}$ and E-glass fibers/PP composites.

\section{Materials and Methods}

\subsection{Materials}

PP granules manufactured by Cosmoplene Polyolefin Company Ltd, Singapore, were collected for this experiment. Figure 1 shows the Molecular structure of polypropylene (PP).

The Okra plant has been collected from Gazipur District (Bangladesh). Around $2.5 \mathrm{~m}$ high and 3 months, Okra plants were collected. After collecting the plants, the middle portion of the stems was separated from it. Then kept the stem under 
the water for retting. After 15-20 days, the stem was degraded properly and it's time to collect the degraded stem. Then washed the Okra degraded stem several times using distilled water and then the Okra fibers were obtained. After that kept the fibers in the open air and afterward reserved it in the fresh container $[32,33]$. Figure 2 shows the image of Okra fiber.

E-glass fiber (woven roving) was collected from SaintGobain Vetrotex India Ltd which was used in this experiment. Figure 3 shows the images of E-glass fiber Figure 3 (a) Mat and Figure 3 (b) roll.

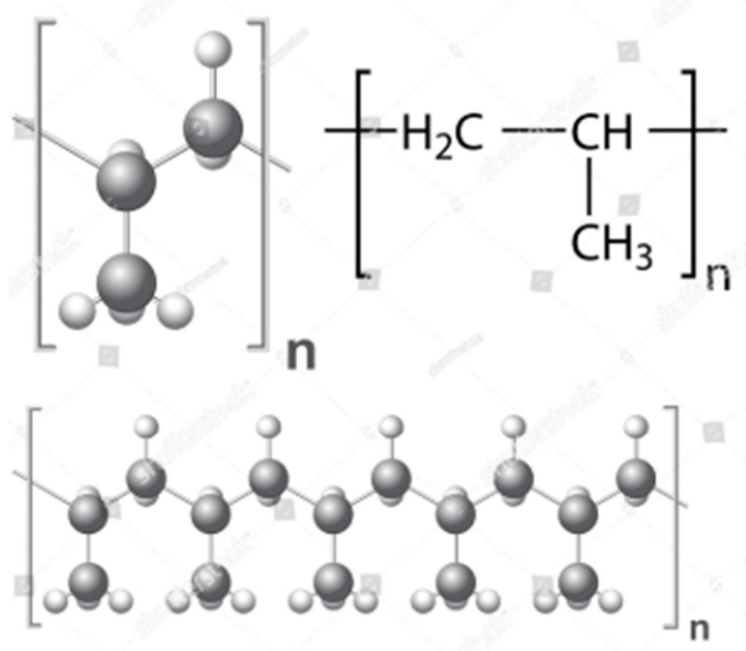

Figure 1. Molecular structure of poly-propylene (PP).

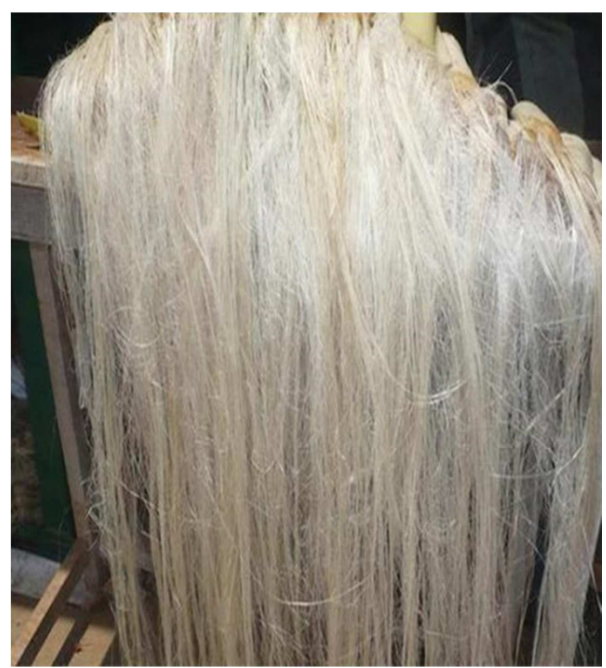

Figure 2. Images of the Okra Fiber.
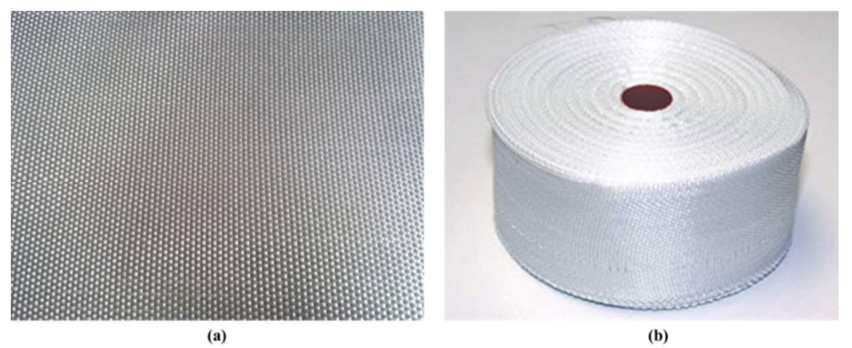

Figure 3. Digital images of E-glass fiber mat (a) and roll (b).

\subsection{Methods}

\subsubsection{Surface Modification}

Surface modification is needed to remove impurities from the natural fibers. Because natural fiber contains lignin, pectin, and wax. So, before the investigation, it is required to remove those impurities from the fibers. Using $5 \% \mathrm{NaOH}$ the Okra fibers were mercerized for 45 minutes at $80^{\circ} \mathrm{C}$. After that treated fibers were dried at room temperature for one week. To remove the moisture, again desiccated in a hot air oven for 10 minutes at the temperature $100^{\circ} \mathrm{C}$.

\subsubsection{Fabrication of Composites}

For making one PP sheet, granules of PP (about $6 \mathrm{~g}$ ) were placed between two steel plates and placed into the heat press (Carver, INC, USA Model 3856). Steel plates were pressed at 5 bar consolidation pressure at $220^{\circ} \mathrm{C}$ for $1 \mathrm{~min}$. After that, at room temperature, the plates were cooled for 5-7 $\mathrm{min}$ for another compression molding machine of the same model. The resulting PP sheets ware cut into desired size $(12 \mathrm{~cm} \times$ $12 \mathrm{~cm}$ ) for composite fabrication. Then, Okra reinforced composites were manufactured by using PP sheet on both sides. For making Okra/PP based composites four layers of Okra fabrics between five sheets of PP were used. The sandwich then placed into the two steel plates and heated at $220^{\circ} \mathrm{C}$ for 5 min using 5 bar pressure. E-glass/PP composites were also fabricated using similar methods in the same heat press.

\subsubsection{Testing of Samples}

i. Determination of Mechanical Properties of the Composites

The tensile properties such as tensile strength (TS), tensile modulus (TM), elongation at break percentage (Eb\%) and bending properties such as bending strength (BS), bending modulus (BM) of the prepared composites were evaluated by using the Hounsfield series $\mathrm{S}$ testing machine (UK) with a cross-head speed of $1 \mathrm{~mm} / \mathrm{s}$ at Institute of Radiation and Polymer Technology Laboratory, Bangladesh Atomic Energy Commission, Dhaka, Bangladesh and the test specimens were prepared according to ASTM-D638-01 standard. Impact strength (IS) of the composites were measured using the Impact tester machine (model: HT8041B IZOD, Serial no.: 7406) pendulum type, Germany and test specimens were prepared according to ASTMD256 method. Hardness was determined by HPE Shore-A Hardness Tester (model 60578, Germany). Using a band saw, text specimens were cut into their required dimension. The dimensions of the test specimen were (ISO 14125): 60 $\mathrm{mm} \times 15 \mathrm{~mm} \times 2 \mathrm{~mm}$.

ii. Water Absorption (Water uptake tests)

Water absorption was done at $25^{\circ} \mathrm{C}$ room temperature. This test was carried out in de-ionized water. Water uptake of Okra fibers were done at room temperature and placed composites into static glass beakers containing $100 \mathrm{ml}$ of deionized water. The size of the specimens was $20 \mathrm{~mm} \times 10$ $\mathrm{mm} \times 2 \mathrm{~mm}$. At $105^{\circ} \mathrm{C}$, the samples were taken out from the de-ionized water and wiped by tissue paper and then dried for 
6 hours and after that weighed the composites. Water absorption was calculated using the following formula:

$$
W=\frac{W_{1}-W_{2}}{W_{2}} \times 100
$$

Where, $W$ is the water absorption (\%), $W_{1}$ denoted the mass of the samples after water treatment, and $W_{2}$ indicated the mass of the specimens before immersion in the water.

iii. Interfacial Properties of the Composites

Single fiber composite of each sample was prepared for one single filament of fiber (Okra, and E-glass fibers) between two sheets of PP. Then sandwich placed between two steel plates and after that heat pressed (Carver, USA) at $220^{\circ} \mathrm{C}$ for $1 \mathrm{~min}$ at 5 bar pressure and the plates were cooled in a separate press (Carver, USA) using 5 bar pressure at room temperature. The thickness of the specimen was $0.40 \mathrm{~mm}$. The single fiber composite specimens' size were $25 \mathrm{~mm} \times 5 \mathrm{~mm} \times 0.40 \mathrm{~mm}$. Then those specimens were loaded on the Universal Testing Machine (Hounsfield series, UK) and after loading it showed repeated breakage of the fiber. For this test, $25 \mathrm{~mm}$ gauge length and $0.25 \mathrm{~mm} / \mathrm{min}$ crosshead speed were used. During the test, a Hitachi microscope was attached to a monitor and using this microscope the whole experiment was monitored. After the end of the experiment, digital images of the breakage of the fibers were taken and these images were taken from the video graphic printer. Fiber fragment length at the saturation point was measured in this experiment. To reach the saturation level, the number of fragments over the $25 \mathrm{~mm}$ gauge length at each load level (using $2 \mathrm{~N}$ increments) was counted. The critical length $\left(l_{c}\right)$ was then measured using this formula:

$$
l_{c}=4 / 3 l_{f}
$$

where $l_{f}$ is the average fragment length; $l_{f}$ was calculated as the monitored length $25 \mathrm{~mm}$ which was divided by the number of breaks observed within that length of the experimental fragment length distribution. The number of fragments had to be counted and after that, using the number of fragments critical length had been calculated. Using tensile testing filaments (the international standard BS ISO 11566), fiber tensile properties were obtained. During the experiment, a single fiber was placed on the paper frame with a gauge length of $25 \mathrm{~mm}$ and then sample was gripped in the tensile machine. The paper section were cut down before starting the test. During the test, $1 \mathrm{~mm} / \mathrm{min}$ crosshead was used. Using Kelly-Tyson and Drzal equations, the IFSS of the composites was calculated. This formula

$$
\tau_{i}=d \times \frac{\sigma_{f}}{2} \times l_{c}
$$

was used to calculate IFSS and this formula was formulated by Kelly and Tyson. In the above formula, $d$ indicated the fiber diameter, $\sigma_{f}$ denoted the single-fiber TS at the critical fragment length $l_{c}$.

\section{Result and Discussion}

\subsection{Water Absorption Behavior of the Composites}

Water absorption test was done by soaking the samples of Okra fiber in a static glass beaker which is contained deionized water and kept the sample inside the beaker at room temperature $25^{\circ} \mathrm{C}$ for around 90 hours. After 10 hours the absorption rate was gained optimum value after that swelling rate became slow and static with the increase of time for treated composite. Figure 4 shows the water absorption of the optimized composites (45\% fiber) against different soaking period. From Figure 4 it was investigated that Okra fiber composite gained the highest water absorption up to $7.1 \%$. For this investigation treated OF/PP fiber was used and that was the reason behind the lower absorption of the composites because after treating the fiber vacant space of fiber filled by polymer (PP). During the water absorption test, some of the hydroxyl groups are replaced inside the composites and the hygroscopicity of lingo-cellulosic fiber is reduced. This replacement occurred due to alkali treatment. Due to mercerization, crystalline part increased in the fiber and in the crystalline part, the hydroxyl groups are cross-linked with each other, so there is no space available to absorb water [11-13].

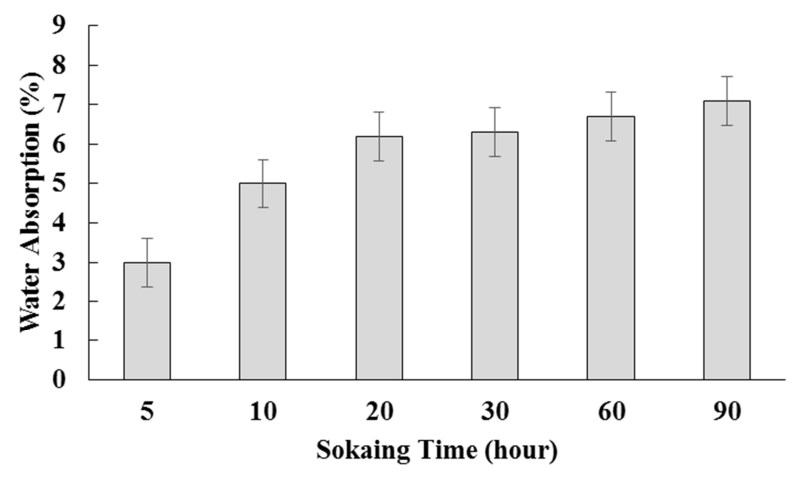

Figure 4. Shows the water absorption of the optimized composites $45 \%$ fiber) against different soaking period.

\subsection{Investigation of Mechanical Properties of the Composites}

\subsubsection{Comparative Studies of the Mechanical Properties the Composites}

The tensile properties of material provide information about how it behaves during the application of axial loading. The mechanical properties of unreinforced PP and treated OF/PP (45\% fiber by wt.) composites were investigated. Table 1 and Table 2 showed the mechanical properties of the composites. 
Table 1. Tensile and bending properties of PP sheet and the composites.

\begin{tabular}{|c|c|c|c|c|c|}
\hline \multirow{3}{*}{ Material } & \multicolumn{5}{|c|}{ Tensile and bending properties } \\
\hline & \multicolumn{3}{|l|}{ Tensile properties } & \multicolumn{2}{|c|}{ Bending properties } \\
\hline & Strength (MPa) & Modulus (GPa) & Elongation at Break (\%) & Strength (MPa) & Modulus (GPa) \\
\hline PP & 21 & 0.53 & 378 & 27 & 1.98 \\
\hline Okra/PP composite & 38.5 & 0.68 & 8.2 & 72.5 & 5.56 \\
\hline E-glass/PP composite & 80 & 5 & 11 & 81 & 10.0 \\
\hline
\end{tabular}

Table 2. Impact strength of the PP sheet and the composites.

\begin{tabular}{lll}
\hline Material & Impact Strength $\mathbf{( k J / \mathbf { m } ^ { 2 } )}$ & Hardness $($ Shore-A) \\
\hline PP & 4.47 & 95 \\
Okra/ PP composite & 22.87 & 97 \\
E-glass/PP composite & 32 & 97 \\
\hline
\end{tabular}

It can be observed from Table 1 that the higher tensile strength of the composites was found when $45 \%$ wt fiber content was used to fabricate the both composites. The tensile strength of the E-glass fiber/PP (45\% wt. fiber content) was $80 \mathrm{MPa}$ and the tensile strength of the Okra/PP (45\% wt. fiber content) was $38.5 \mathrm{MPa}$. The observed result showed E-glass fiber showed higher tensile strength $80 \mathrm{MPa}$ because E-glass fiber and matrix interaction was higher than Okra fiber and matrix interaction.

The tensile modulus of the E-glass fiber/PP based composites was increased a lot compared to Okra fiber/PP based composites. The tensile modulus of the E-glass fiber/PP (45\% wt. fiber content) was $5.0 \mathrm{GPa}$ and the tensile modulus of the Okra/PP ( $45 \%$ wt. fiber content) was 0.68 $\mathrm{GPa}$. The effect of the filler content and matrix mainly responsible for enhancement of the tensile modulus of the composites and also preparation technique of the composites such as compression molding technique was also helped to increase the tensile modulus of the composites.

The effect of fiber content $45 \%$ wt. on the bending properties of compression molded both composites showed in the Table 1. It can be observed that the bending properties of the OF/PP and E-glass/PP composites increased when 45\% wt. filler (fiber) content was used. And it was observed that after using $45 \%$ wt. fiber content, composites attributed better surface area of the fiber in the matrix and the more fiber content was used for fabricating the composite, it was expected that the more fibers can able to share the load effectively with crystal-line fibrils which was applied in the matrix. From the Table 1, it can be seen that E-glass fiber/PP composites showed better bending strength compared to Okra/PP fiber based composites.

The effect of filler (fiber) content on the elongation at break of E-glass/PP composites processed through compression molding technique. But the elongation at break for both composites decreases with increase in fiber content. The elongation at break of the E-glass fiber/PP (45\% wt. fiber content) was $11 \%$ and the elongation at break of the Okra/PP (45\% wt. fiber content) was $8.2 \%$. When $45 \%$ wt. fiber content used, elongation at break of the composites started to decrease. Increasing fiber content in PP matrix resulted in the hardening and stiffening of the composites. It has been reported that the higher tensile modulus of the composites, the lower the elongation at break of the composites. From Table 1, it was observed that Okra fiber/PP composites decreased more compared to E-glass/PP fiber composites. Because natural fiber based composites stiffer than E-glass/PP based composites.

The hardness (Shore A) of compression molded (45\% wt. fiber) E-glass/PP and Okra/PP composites are showed in the Table 2. It is evident that the hardness of both composites increased with the increment of the fiber content. Here $45 \%$ wt. fiber content results showed in the table. $45 \%$ wt. fiber content was maximum fiber content for both composites. That's why both composites showed higher hardness like 97 shore A. It can be observed that the hardness of the PP based composites increase with the increment of the filler content which was incorporated with PP. Stiffer filler also responsible for the enhancement of the hardness of the PP. Therefore more the adhesion between the matrix and filler (i.e. E-glass fiber and Okra fiber), the greater will be the hardness of the composites.

It was revealed the value of TS, TM, Eb (\%), BS, BM, IS and hardness was $21 \mathrm{MPa}, 0.53 \mathrm{MPa}, 378 \%, 27 \mathrm{MPa}, 1.98$ $\mathrm{GPa}, 4.47 \mathrm{KJ} / \mathrm{m}^{2}$, and 95 Shore-A respectively for PP sheet. From Table 1, it was investigated that the mechanical properties of the Okra fiber (OF)-based composite was increased using the PP as a matrix. The tensile strength (TS) and tensile modulus (TM) of the treated OF/PP improved to $83.33 \%$ and $28.30 \%$ respectively than the PP matrix. From the analytical data, it was also revealed that bending strength (BS), bending modulus (BM) and impact strength (IS) also increased to $168.52 \%, 180.81 \%$, and $411.63 \%$ respectively for $\mathrm{OF} / \mathrm{PP}$ composites over the PP matrix. On the other hand, due to the lower elongation of the natural fibers, $\mathrm{Eb} \%$ was drastically reduced. The value of hardness was found to be 97 (Shore-A) for OF/PP fiber composite which is higher than the hardness of the PP matrix. During the alkali treatment, the interface between matrix and fiber was improved and mercerization also decreases the diameter of the fibers and also increases the roughness of the surface which was the main reason for the increment of the mechanical properties of the composites.

The mechanical properties such as tensile, bending, impact, and hardness of the PP sheet, OF/PP, and E-glass fiber/PP composites were evaluated and the values are given in Table 1 and Table 2. E-glass based composites made of $45 \%$ fiber significantly improved the mechanical properties 
(TS, TM, BS, BM, and IS). E-glass composites gained $280.95 \%$ increase in TS and $843 \%$ increase in TM over that of the matrix PP. It was also studied that BS, BM, and IS also improved by $200 \%, 405.1 \%$, and $615.88 \%$ respectively than that of the matrix material PP. On the other hand, the percentage elongation at break $(\mathrm{Eb} \%)$ was reduced significantly because of low $\mathrm{Eb} \%$ of the fibers compared to the PP matrix. Since PP and E-glass fiber both are hydrophobic in nature. That's the reason E-glass fiber-based composite showed higher mechanical properties when it fabricated with PP matrix. Shore hardness of the E-glass fiber is more than PP based composite.

E-glass-based composites showed in Table 1 and Table 2 significantly higher TS, TM, BS, BM, and IS over the OF/PP composites. It was revealed that the E-glass fiber/PP composites were found to have $107.79 \%$ and $635.29 \%$ improvement of TS and TM over the OF/PP composites. It was also reported that $\mathrm{BS}, \mathrm{BM}, \mathrm{Eb} \%$ and IS also improved by $11.72 \%, 79.85 \%, 34.15 \%$, and $39.92 \%$ than that of the $\mathrm{OF} / \mathrm{PP}$ composites. Hardness (Shore A) of the E-glass composites and the hardness OF/PP composites are same.

\subsubsection{Comparative Studies of the Interfacial Properties of the Composites}

SEM micrographs studies were carried out to understand the interfacial bonding of the composites and fiber-matrix adhesion inside the composites. Figure 5 (a) showed the SEM images of the fractured sides of the corresponding E-glass fiber/PP composites (45\% fiber) and Figure 5 (b) showed the SEM images of the fractured sides of the corresponding Okra fiber/PP composites ( $45 \%$ fiber). The SEM image of the fracture surface explained that the fiber pull-out was quite low and fractures between E-glass fibers and PP matrix were clearly evident which indicates excellent fiber-matrix adhesion. It also reported very few holes in the matrix suggesting very good bonding between E-glass fiber and the polymer matrix.

On the other hand, the SEM images of the Okra fiber/PP composite the bonding between the mercerized fiber and the PP matrix which was demonstrating an improved fibermatrix bonding with Okra fiber. As a result enhanced stress transfer occurred between the reinforcing fibers and matrix material. SEM images Figure 5 (b) shows the debonding of the OF and PP. This figure showed that the bonding between PP matrixes and reinforcing OF fiber can be developed and this interfacial bonding showed strong bonding between the Okra fiber reinforcement and PP matrix which significantly affect the physico-mechanical behaviors of composites. Therefore, it was reflected that the tensile, bending and impact behaviors of the composite material can be further optimized using the appropriate coupling agents.

From the SEM images of the fracture surfaces of both Eglass/PP and OF/PP clearly showed and explained the interfacial properties of the composites as well as explains why Okra fiber reinforced-based composites have low mechanical and interfacial properties as compared to the Eglass-based composites. From the comparative studies of the mechanical properties between $\mathrm{OF} / \mathrm{PP}$ and E-glass fiber/PP composites, it was found that the mechanical properties of Okra Fiber reinforced based composites are quite low compared to that of the E-glass-based composites. So, further investigation will have to be carried out to reduce the hydrophilic nature of $\mathrm{OF}$ and to try and improve the interfacial bonds between Okra and PP but retaining the inherent biodegradable properties of Okra fibers. This research opens new doors for further study to bring the mechanical properties of Okra composites closer to that of the E-glass-based composites.

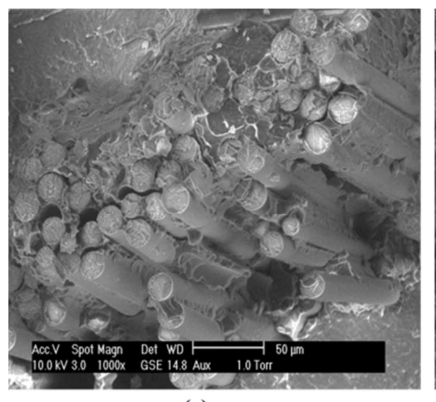

(a)

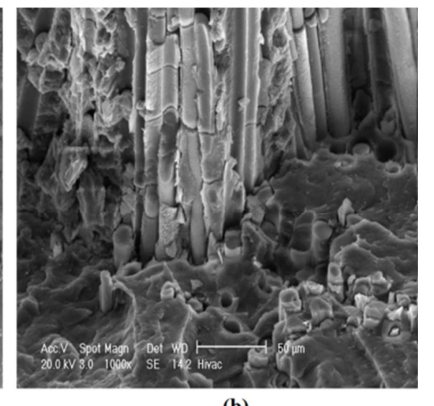

(b)
Figure 5. SEM images of fracture surface of E-glass fiber/PP composite (a) and (b) fracture surface of $O F / P P$ composite.

\section{Conclusion and Recommendation for Future Study}

Water uptake tests of Okra fibers were studied and it was found that Okra fiber gained optimum amounts of water absorption but it takes lots of time. Okra/PP based composites ( $45 \%$ fiber by weight) were fabricated by compression molding and the mechanical properties were evaluated. TS, TM, elongation at break (\%), BS, BM, and IS of the composites were found to be $38.5 \mathrm{MPa}, 0.68 \mathrm{GPa}$, $11 \%, 72.5 \mathrm{MPa}, 5.56 \mathrm{Gpa}$, and $22.87 \mathrm{~kJ} / \mathrm{m}^{2}$, respectively. Then E-glass fiber mat-reinforced PP-based composites $(45 \%$ fiber by weight) were fabricated and the mechanical properties were investigated. For E-glass-based composites, TS, TM, Eb (\%), BS, BM, and IS of the composites were found to be $80 \mathrm{MPa}, 5 \mathrm{GPa}, 11 \%, 81 \mathrm{MPa}, 10 \mathrm{GPa}$, and 32 $\mathrm{kJ} / \mathrm{m}^{2}$, respectively. From this investigation, it was found that the mechanical properties of E-glass-based composites had almost double the values for TS, TM, BS, BM, and IS compared to that of the Okra/PP based composites. SEM images of the fracture sides of the composites supported the fact that Okra fiber-based composites had poorer fiber-matrix adhesion than the E-glass fiber/PP-based composites. From this comparative study, it can be observed that E-glass fiber PP based composites showed better performance rather than Okra fiber/PP based composites. In this research work, there are some limitation identified, Okra fiber is hyperbolic in nature so that it showed less mechanical properties compared to E-glass fiber/PP based composites. This can be overcome by the chemical processing of the fibers and also gamma radiation can be applied in the composites to improve the mechanical properties of the Okra/PP based composites. So, 
future research study will be carried out to improve the mechanical properties of the composites using gamma radiation. After proper chemical and gamma radiation treatment, these both materials (E-glass/PP and OF/PP) can be used for structural applications and because of the biodegradable in nature Okra fiber based composites can be used in the packaging industry as well.

\section{Author Contributions}

Author 1: Kamrun N. Keya

i. Conceived and designed and analysis data

ii. Collected data

iii. Performed the analysis

iv. Wrote the paper

v. Revised this manuscript

Author 2: Nasrin A. Kona

i. Contributed data and analysis tools

ii. Co-wrote the paper

iii. Helped to revise the manuscript

Author 3: Ruhul A. Khan

i. Supervised the whole research work

ii. Corresponding Author

iii. Review the manuscript

\section{Conflict of Interest}

The authors have declared that there is no conflict of interest exists in this works.

\section{Acknowledgements}

This work was supported by polymer composite laboratory, Institute of Radiation and Polymer Technology, Bangladesh Atomic Energy Commission, Dhaka, Bangladesh.

\section{References}

[1] Keya, K. N., Kona, N. A., Koly, F. A., Maraz, K. M., Islam, M. N., \& Khan, R. A. (2019), Natural fiber reinforced polymer composites: history, types, advantages and applications. Materials Engineering Research, 1 (2), 69-85.

[2] V. Muthukumar, R. Venkatasamy, A. Sureshbabu, D. Arunkumar (2011), A Study on Mechanical Properties of Natural Fiber Reinforced Laminates of Epoxy (Ly 556) Polymer Matrix Composites, International Journal of Production Technology and Management Research, 2 (2), 67-72.

[3] Mishra, S., Mohanty, A. K., Drzal, L. T., Misra, M., Parija, S., Nayak, S. K. et al. (2003), Studies on Mechanical Performance of Biofibre/Glass Reinforced Polyester Hybrid Composites, Compos. Sci. Technol., 63 (10), 1377-1385.

[4] Cantero, G., Arbelaiz, A., Llano-Ponte, R. and Mondragon, I. (2003), Effects of Fiber Treatment on Wettability and Mechanical Behavior of Flax/Polypropylene Composites, Compos. Sci. Technol., 63 (9), 1247-1254.
[5] Joseph, P. V., Joseph, K. and Thomas, S. (2002), Short Sisal Fiber Reinforced Polypropylene Composites: The Role of Interface Modification on Ultimate Properties, Compos. Interf. 9 (2): 171-205.

[6] Mohanty, A. K., Misra, M. and Hinrichsen, G. (2000), Biofibers, Biodegradable Polymer and Biocomposites: An Overview, Macromol. Mater. Eng., 276 (1), 1-24.

[7] Bullions, T. A., Gillespie, R. A., Price-O'Brien, J. and Loos, A. C. (2004), The Effect of Maleic Anhydride Modified Polypropylene on the Mechanical Properties of Feather Fiber, Kraft Pulp, Polypropylene Composites, J. Appl. Polym. Sci., 92 (6), 3771-3783.

[8] T. Raja, Dr. P. Anand, M. Karthik and M. Sundaraj (2017), Evaluation of Mechanical Properties of Natural Fibre reinforced Composites - A Review, International Journal of Mechanical Engineering and Technology (IJMET), 8 (7), 915-924.

[9] Taha, I., \& Ziegmann, G. (2006), A Comparison of Mechanical Properties of Natural Fiber Filled Biodegradable and Polyolefin Polymers. Journal of Composite Materials, 40 (21), 1933-1946.

[10] Shrikant M. Harle (2014), The Performance of Natural Fiber Reinforced Polymer Composites: Review, International Journal of Civil Engineering Research, 5 (3), 285-288.

[11] A. N. M. Masudur Rahman, Shah Alimuzzaman, Ruhul A. Khan, Md. Ershad Khan and Sheikh Nazmul Hoque (2018), Fabrication, Mechanical Characterization and Interfacial Properties of Okra Fiber Reinforced Polypropylene Composites, International Journal of Engineering Materials and Manufacture, 3 (1), 18-31.

[12] Rahman, A. N. M. M., Alimuzzaman, S., \& Khan, R. A. (2019), Improvement of Physical, Mechanical and Thermal Properties of Okra Fiber/Polypropylene Composites by UV Radiation. Journal of the Institution of Engineers (India): Series E.

[13] Alam, M. S., \& Khan, G. A. (2007), Chemical analysis of Okra bast fiber (Abelmoschus esculentus) and its physicochemical properties. Journal of Textile and Apparel Technology and Management, 5 (4).

[14] Joseph, P., Joseph, K., \& Thomas, S. (2002), Short sisal fiber reinforced polypropylene composites: the role of interface modification on ultimate properties. Composite Interfaces, 9 (2), 171-205.

[15] Khan, G. A., Shaheruzzaman, M., Rahman, M., Razzaque, S. A., Islam, M. S., \& Alam, M. S. (2009), Surface modification of Okra bast fiber and its physico-chemical characteristics. Fibers and Polymers, 10 (1), 65-70.

[16] Kamrun N. Keya, Nasrin A. Kona and Ruhul A. Khan (2019), Comparative Study of Jute, Okra and Pineapple Leaf Fiber Reinforced Polypropylene Based Composite, Advanced Materials Research, 1155, 29-40.

[17] N. Srinivasababu, K. Murali Mohan Rao and J. Suresh Kumar, Tensile properties characterization of okra woven fiber reinforced polyester composites, International Journal of Engineering, (IJE), 3 (4), 403-412.

[18] I. V. Surendra, K. Venkateswara Rao and K. V. P. P. Chandu (2015), Fabrication and Investigation of Mechanical Properties of Sisal, Jute \& Okra Natural Fiber Reinforced Hybrid Polymer Composites, International Journal of Engineering Trends and Technology (IJETT), 19 (2), 116-120. 
[19] Porana Upendra and G. Satyanarayana (2019), Mechanical Behavior and Analysis of Okra and Pineapple Reinforced Composite Materials, 6 (6), 3895-3906.

[20] James Paul. K, IISd. Abdul Kalam (2016), Mechanical Properties of Okra Fiber Reinforced Composites Using Fem, International Journal of Advanced Research in Mechanical Engineering \& Technology, 2 (2), 28-31.

[21] Miah, M., Ahmed, F., Hossain, A., Khan, A., and Khan, M. A. (2005), Study on mechanical and dielectric properties of jute fiber reinforced low-density polyethylene (LDPE) composites. Polymer-Plastics Technology and Engineering, 44 (8-9), 14431456.

[22] Mishra, A., \& Pal, S. (2007). Polyacrylonitrile-grafted Okra mucilage: A renewable reservoir to polymeric materials, Carbohydrate Polymers, 68 (1), 95-100.

[23] Raghu, K., Noorunnisa Khanam, P., and Venkata Naidu, S. (2008), Chemical Resistance Studies of Silk/Sisal FiberReinforced Unsaturated Polyester-Based Hybrid Composites. Journal of Reinforced Plastics and Composites, 29 (3), 343345 .

[24] Seelam Pichi Reddy and A. Chennakesava Reddy (2016), Tensile and Flexural Strength of OKRA Fiber Reinforced Polymer Composites, International Journal of Engineering and Management Research, 6 (1), 491-495.

[25] Yusri H Muhammad, Sahrim Ahmad, Mimi A Abu Bakar, Abdullah A Mamun and Hans P Heim (2015), Mechanical properties of hybrid glass/kenaf fibre-reinforced epoxy composite with matrix modification using liquid epoxidised natural rubber, Journal of Reinforced Plastics and Composites, 34 (11), 896-906.

[26] E. Fortunati, D. Puglia, M. Monti, C. Santulli, M. Maniruzzaman, M. L. Foresti, A. Vazquez and J. M. Kenny (2013), Okra (Abelmoschus esculentus) Fibre Based PLA Composites: Mechanical Behaviour and Biodegradation, Journal of Polymers and the Environment, 21 (3), 726-737.

[27] Zhou, X. F., Wagner, H. D. and Nutt, S. R. (2001), Interfacial Properties of Polymer Composites Measured by Push-Out And Fragmentation Tests, Compos.: Part A, 32 (11), 1543-1551.

[28] Greenfield, M. J., Pedicini, A. and Penn, L. S. (2000), Development of a Single Fiber Fragmentation Test for High Strain Rates, Int. J. Adhesion Adhesives, 20 (5), 403-407.

[29] Mohanty, A., Khan, M. A., \& Hinrichsen, G. (2000), Surface modification of jute and its influence on performance of biodegradable jute-fabric/Biopol composites. Composites Science and Technology, 60 (7), 1115-1124.

[30] Mohanty, A., Misra, M., \& Hinrichsen, G. (2000), Biofibres, biodegradable polymers and biocomposites: an overview. Macromolecular Materials and Engineering, 276 (1), 1-24.

[31] Cabral, F. S., Paiva, M. C., Nunes, J. P. and Bernardo, C. A. (2003), A Novel Technique for the Interfacial Characterization of Glass Fiber-Polypropylene Systems, Polym. Testi, 22 (8), 907-913.
[32] I O Eze and I O Igwe (2018), Comparison of Some Mechanical Properties of Injection and Extrusion Moulded Pineapple Leaf Powder Filled High Density Polyethylene, European Journal of Advances in Engineering and Technology, 5 (4), 236-243.

[33] Potluri, R., James Paul, K., Abdul kalam, S., \& Prasanthi, P. (2017), Mechanical Properties Characterization of Okra Fiber Based Green Composites \& Hybrid Laminates. Materials Today: Proceedings, 4 (2), 2893-2902.

[34] X Ma, J Yu and JF Kennedy (2005), Studies on the Properties of Natural Fibre- Reinforced Thermoplastic Starch Composites and Carbohydrate Polymers, Journal of Science and Technology, 62, 119-124.

[35] BH Lee, HJ Kim and WR Yu (2009), Fabrication of Long and Discontinuous Natural Fibre Reinforced PolypropyleneBiocomposites and their Mechanical Properties, Fibres and Polymers, Polymer Science and Technology, 10, 283-298.

\section{Biography}

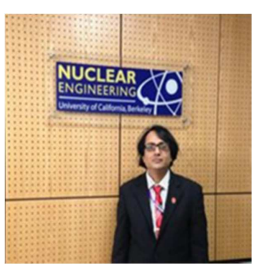

Ruhul Amin Khan, is a director of Institute of Radiation and Polymer Technology, Bangladesh Atomic Energy Commission, Dhaka, Bangladesh. His research interests lie in radiation, polymer, natural fiber and synthetic fiber based composites. $\mathrm{He}$ completed his $\mathrm{PhD}$ degree from University of Nottingham, works as a Post Doc (Montreal, Canada), visiting scientist (UBC, Vancouver, Canada), visiting scholar (University of California, Berkeley, USA) and UNESO Fellow (TIT, Japan). He is the Editor-in-Chief/Editorial Board Member of many peer reviewed journals and his area of expertise credits him with many publications in national and international journals.

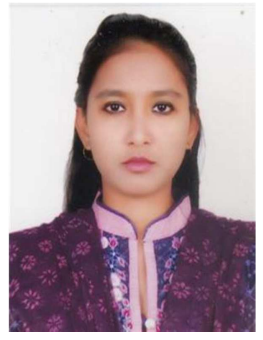

Kamrun Nahar Keya, obtained her bachelor's degree from Military Institution of Science and Technology, Mirpur, Dhaka, Bangladesh in 2016. She is currently work as a research fellow with Dr. Ruhul A. Khan. Her research interests' lie in polymer concrete, natural fiber and synthetic fiber based composites, fiber reinforced based concrete structure. Her research is centered on fabrication and mechanical characterization of various types of natural fiber polymer based composites. She has author and coauthor over 6 international publications.

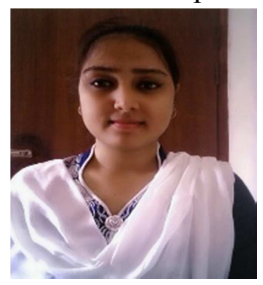

Nasrin Afroz Kona, is currently work as a research fellow with Dr. Ruhul A. Khan. Her research is centered on fabrication and mechanical characterization of jute fiber polymer based composites. She has author and coauthor over 3 international publications. 